\title{
TAFSIR MORAL DALAM KIDUNG PANGILING KARYA KIAI IMAM MALIK
}

\author{
Miftakhur Ridlo \\ Institut Agama Islam (IAI) Uluwiyah Mojokerto \\ Email : rheydlo@yahoo.co.id Hp : 085648634362
}

\begin{abstract}
Abstrak
Kiai Imam Malik adalah penulis Kidung Pangiling yang bertempat tinggal di desa Losari kecamatan Mojosari kabupaten Mojokerto. Beliau mendirikan padepokan yang bernama Padepokan Mayangkoro Pondok Pesantren Sambung Sari Noto Projo Majapahit Bangkit Nusantara Jaya. Kidung Pangiling ini adalah syiiran yang biasa dilagukan dan didakwakan melalui speaker aktif di dalam Masjid Wisnu Manunggal yang dilakukan setiap pagi dan sore hari. Kiai Imam Malik menciptakan kidung pangiling bertujuan untuk memberikan nasehat dan pengingat kepada masyarakat pada durasi waktu 1997 - 2006. Tafsir moral dalam Kidung Pangiling karya Kiai Imam Malik secara garis besar menjelaskan tentang fenomena moralitas yang mengalami degradasi luar biasa yang terjadi dalam masyarakat. Khususnya pada tahun 1999, 2000 dan 2001, karena masa itu terjadi perang saudara di beberapa tempat, seperti di Kalimantan, Sulawesi dan Ambon. Beberapa bait dalam Kidung: Akeh wong kalab gak podho kroso Mulai sasi songo tahun 99 Wis podho bingung wedi ciloko Ora biso nyukuri nikmat seng teko, Tatanan anyar sing salah kaprah Sing wis dadi umum, bener tak lumrah Sebab ilange bukum lan sejarah Karek ngenteni tekane banjir darah.
\end{abstract}

\begin{abstract}
Kiai Imam Malik is the author of Kidung Pangiling who resides in Losari village, Mojosari district, Mojokerto district. He founded a hermitage named Padepokan Mayangkoro Islamic Boarding School Connect Sari Noto Projo Majapahit Bangkit Nusantara Jaya. This Pangiling Song is a syiiran who is used to being heard and charged through active speakers in the Wisnu Manunggal Mosque which is held every morning and evening. Kiai Imam Malik created the pangiling bymn aimed at giving advice and reminders to the people during the $1997-2006$.
\end{abstract}

Nazhruna: Jurnal Pendidikan Islam

Vol. 2 No 1 2019. Issn: 2614-8013. Hal. 68-86

DOI: 10.3153 /nzh.v2i1.231 
The moral interpretation in Kidung Pangiling by Kiai Imam Malik broadly explained the phenomenon of morality which experienced tremendous degradation that occurred in society. Especially in 1999, 2000 and 2001, because there were civil wars in several places, such as in Kalimantan, Sulawesi and Ambon. Several verses in song: Akeh wong kalab gak podho kroso Mulai sasi songo tabun 99 Wis podho bingung wedi ciloko Ora biso nyukuri nikmat seng teko, Tatanan anyar sing salah kaprah Sing wis dadi umum, bener tak lumrah Sebab ilange hukum lan sejarah Karek ngenteni tekane banjir darah.

\section{Latar Belakang}

Kidungan adalah gaya nembang asli khas Jawa Timuran yang unik, menggelitik, jenaka, kadang penuh dengan sindiran halus sampai terang terangan atau sarkasme, tidak jarang berupa kritik yang membangun, memotivasi dan tidak jarang juga berupa ejekan yang tidak membuat pendengarnya merasa perlu marah tapi malah tergelitik untuk akhirnya menyadari betapa mengenanya kritikan dalam kidung tersebut. Kidungan sering dijadikan sarana ampuh untuk memperbaiki kondisi ataupun kebiasan, pola atau gaya hidup segolongan tertentu dalam masyarakat Jawa Timur yang dianggap tidak pas pada zamannya atau kurang pas dengan adat kebiasaan warga setempat. ${ }^{1}$

Kidung adalah doa, dan dalam doa seseorang harus yakin bahasa apa untuk menggunakannya (mengerti berbicara), tentu dengan tinggi konfrontasinya, dan pahami artinya doa digunakan. Dalam Sejarah Sunan Kalijaga membuat mantra dengan bahasa Jawa karena bahasa Jawa doa akan mudah dimengerti dan dipercaya jika bahasanya dimengerti. Sunan Kalijaga dikenal sebagai wali yang menggabungkan budaya Jawa dengan nilai Islam untuk menyebarkannya agama Islam. ${ }^{2}$

Kidung dalam Kamus Besar Bahasa Indonesia berarti nyanyian, lagu, syair yang dinyanyikan. Kidung biasanya dinyanyikan pada saat upacara adat dan agama, dimana makna da nisi dari kidung adalah pemujaan kepada Tuhan Yang Maha Esa. Apabila menyanyikan atau mendengarkan kidung dengan penuh penghayatan atau kekhusukan maka makna dari kidung dapat membuat tenang pada setiap pendengarnya. Kidung yang berirama lembut saat

\footnotetext{
1 Ayu dkk, Kajian Interaksionisme Simbolik Kidung Jula Juli Pada Pementasan Ludruk Irama Budaya Surabaya, Jurnal Ilmiah : Fonema, Vol 4 No. 2, Bulan Desember 2017, 79

${ }^{2}$ Hafid Zuhdan Bahtiar, Kidung : Myth of Welfare for Kutubuk People in Kudus Regency, Harmonia : Journal of Art Research and Eduacation 14 (2) 2014, 115
} 
didengarkan akan membawa perasaan kearah ketenangan. ${ }^{3}$ Kidung kebayakan dipakai untuk menyebut naskah - naskah Jawa Tengahan, yang pada umumnya mengisahkan legenda - legenda romantic tentang era Majapahit. Kidung sebagai nyanyian disebutkan dalam prasasti periode awal, juga disebutkan dalam sejumlah teks prosa Jawa Kuno. ${ }^{4}$

Tujuan dari lagu - lagu ini digunakan untuk media berdoa bagi Allah, dan media untuk mendekatkan Allah, kidung doa yang bernilai - nilai agama yang terkandung dalam lirik untuk kehidupan masyarakat. Kidung pada waktu itu adalah doa yang berkaitan tujuan agama dalam Islam. Karena itu warisan budaya yang berharga tinggi perlu dilestarikan dengan baik karena arti dari lagu - lagu Kidung. Doa memiliki manfaat bagi kehidupan kita, bukan hanya untuk bernyanyi atau menghibur tetapi juga untuk beribadah kepada Allah. ${ }^{5}$ Kidung merupakan sebuah karya sastra naratif yang ditulis menggunakan bahasa Jawa yang muncul pada zaman Jawa pertengahan, sekitar abad ke - 15 atau pada masa kerajaan Majapahit akhir, bahasa Jawa pertengahan bukanlah sumber atau bahasa proto dari bahasa Jawa Baru. Bahasa Jawa pertengahan dan bahasa Jawa baru merpakan bahasa umum selama periode Hindu Jawa sampai runtuhnya kerajaan Majapahit. Sastra kidung menggunakan bahasa Jawa pertengaha sebagai media pengantar kepada masyarakat. ${ }^{6}$

Karya sastra dalam masyarakat berfungsi sebagai hiburan atau menghibur dan memiliki manfaat, dalam hal ini kidung suci kelamaan disatu sisi berfungsi menghibur atau sarana hiburan dan pada sisi lain sekaligus memberi manfaat berupa tuntutan hidup yang baik. Selain itu, kidung juga erat kaitannya dengan bidang agama, filsafat, mitologi, sejarah, etika dan keindahan. Teks sastra dalam hal ini kidung adalah bentuk nyayian yang berisi tentang ajaran etika, moral dan sebagainya yang sangat berguna sebagai tuntunan dalam bertingkah laku khususnya dalam mendidik generasi bangsa dalam upaya membentuk sumber da manusia yang berkualiatas. Selain itu teks ini juga memiliki fungsi religi yang terkait dengan budaya agama

\footnotetext{
${ }^{3}$ I Wayan Artana, Pengarub Budaya Bali Kidung Warga Sari TErhadap Tekanan Darah Pada Lansia di Banjar Celuk. Desa Dalung Badung, Jurnal Dunia Kesehatan, Vol 5 Nomor 2, 40

${ }^{4}$ Nurhata, Naskah Kidung Nabi : Analisis Tema dan FUngsi Sosial, Metasastra : Jurnal Penelitian Sastra, Vol. 10, No. 1, Juni 2017, 46

${ }^{5}$ Satriyo Nugroho Agung, A Semantic Analysis of Denotative Meaning in Kidung DOA Song by Sunan Kalijaga, Jurnal Ilmiah Bahasa dan Sastra, Vol 3, No. 1, Juni 2016, 3

${ }^{6} \mathrm{Ni}$ Nyiman Tanjung Traeni, Bentuk, Fungsi dan Mana Tradisi Lisan "Mabebasas" dalam Upacara Keagamaan di Jawa Timur, (Surabaya : Jurnal Balai Bahasa Surabaya, 2011), 16
} 
setempat. Dengan demikian jelas bahwa karya sastra tersebut memiliki pera dalam msyarakat.

Moral berasalh dari bahasa Latin mores, kata jamak dar mos, yang berarti adat kebiasaan. Dalam KBBI moral menyaran pada pengertian (ajaran tentang) baik buruk yang diterima umum mengenai perbuatan, sikap, kewajiban, dan sebagainya: akhlak, budi pekerti, susila. Menjelaskan karata "moral" secara etimologi sama dengan "etika" walaupun bahasanya aslinya berbeda. Moral dapat diartikan nilai - nilai dan norma yang menjadi pegangan bagi seseorang tau suatu kelompok dalam mengatur tingkah lakunya. $^{7}$

Istilah moral dikaitkan dengan motif, maksud dan tujuan berbuat. Moral berkaitan dengan niat, sedangkan etika adalah studi tentang moral. Etika terkait dengan moral dan tingkah laku. Etika juga mengenai rasa belas kasih dan simpati tentang memastikan kehidupan yang lebih baik berbagi dengan yang lainnya. Norma dapat dibedakan menjadi beberapa hal, yaitu norma sopan santun, norma hukum dan norma moral. Norma sopan santun menyangkut tentang sikap lahiriah manusia, kemudian norma hukum adalah norma yang dituntut dengan tegas oleh masyarakat karena demi keselamatan dan kesejahteraan umum. Norma moral adalah tolak ukur yang dipakai oleh masyarakat untuk mengukur kebaikan seseorang, pesan moral sastra lebih memberat pada sifat kodrati manusia yang hakiki, bukan pada aturan aturan yang dibuat, ditentukan dan dihakimi oleh manusia. ${ }^{8}$

Secara lengkap moral sebagai sesatu yang berhubungan dengan norma - norma perilaku yang baik atau benar dan salah menurut keyakinan keyakinan etis pribadi atau kaidah - kaidah sosial, ajaran mengenai baik perbuatan dan kelakuan. Moral yang berlaku dalam masyarakat merupakan tuntutan bagi setiap individu dalam menyesuaikan diri terhadap lingkungannya. Individu yang dianggap dapat memenuhi tuntutan masyarakat adalah individu yang tidak hanya memikirkan kepuasan kebuthan pribadinya, tetapi juga memperhatikan kepentingan masyarakatnya. Moral ini kemudian

\footnotetext{
${ }^{7}$ Susana Fitriani Lado dkk, Analisis Struktur dan Nilai - Nilai Moral yang terkandung Dalam Cerpen Ten Made Todoke Karya Yoshida Genjiro, Jurnal Japanese Literature Volume 2, Nomor 2, Tahun 2016, 7

${ }^{8}$ Dwi Maftuhatul I'anah, Aspek Moral Dalam Novel Mimilan Mintuna Karya Remy Sylado Tinjauan Sosiologi Sastra
} 
menjadi pegangan bagi sesorang atau kelompok dalam mengatur tingkah lakunya. ${ }^{9}$

Moral dalam karya sastra biasanya mencerminkan pandangan hidup pengarang yang bersangkutan, pandangan engarang tentang nilai - nilai kebenaran yang ingin disampaikan kepada pembaca. Moral dalam cerita dimaksudkan sebagai suatu saran yang berhubungan dengan ajaran moral tertentu yang bersifat praktis, yang dapat diambil (dan ditafsirkan) lewat cerita yang bersangkutan oleh pembaca. Ia merpakan petunjuk yang sengaja diberikan oleh pengarang tentang berbagai hal yang berhubungan dengan masalah kehidupan, seperti sikap, tingkah laku, dan sopan santun pergaulan. Petunjuk itu bersifat praktis karena dapat ditemukan dan dilhat modelnya dalam kehidupan nyata, sebagaimana yang ada dalam cerita lewat sikap dan tingkah laku para tokohnya.

Nilai moral dalam karya sastra yang ditawarkan pengarang dalam berbagai jenis dan wujudnya tersebut dapat disampaikan oleh pearang secara langsung atau tidak secara langsung. Bentuk penyampaian pesan secara langsung, dengan memakai teknik uraian, pengarang mendskripsikan perwatakan tokoh atau tokoh - tokoh cerita yag bersifat "memberi tahu" atau memudahkan pembaca untuk memahaminya. Sementara itu, bentuk penyampaian pesan tidak secara langsung adalah jika pesan moral yang disampaikan pengarang itu hanya tersirat dalam cerita, berpadu secara koherensif dengan unsur - unsur cerita yang lain, atau pengarang tidak menyampaikan pesannya secara jelas. Nilai moral atau norma memiliki beberapa tingkatan, pertama isi adalah makna atau maksud dan fungsi atau peran. Kedua adalah nilai ata norma, yang dapat diinferensikan dari makna atau maksud dan fungsi atau peran dengan adanya keyakinan terhadap nilai atau norma itu. Tingkatan ketiga adalah kearifan lokal yang merupakn penggunaan nilai dan norma budaya dalam menata kehidupan sosial secara arif. $^{10}$

Jenis dan wujud nilai moral dalam karya sastra sangat beragam, hal ini tergantung pada keinginan, keyakinan, dan interes pengarangnya sehingga jeis dan wujud nilai - nilai moral tersebut dapat mencakup seluruh persoalan hidup dan kehidupan, baik moral tentang hubungan manusia dengan

\footnotetext{
9 Uswatun Hasanah, Nilai Moral Dalam Saq Al - Bambu Karya Sand Al - San'usi, Adabiyyat : Jurnal Bahasa dan Sastra Vol. I, No. 1, Juni 2017, 119

10 Een Nurhasanah, Nilai - nilai Kearifan Lokal Dalam Tia Nyanyian Pembuka Pertunjukan Tari Jaipong, Prosiding Seinar Nasional Pendidikan FKIP UNTIRTA 2017, 435
} 
Tuhannya, hubungan manusia dengan sesama manusia, maupun hubungan manusia dengan lingkungan alamnya. ${ }^{11}$ Untuk itu yang dimaksud nilai moral dalam penelitian ini adalah berbagai jenis dan wujud ajaran yang ebrsifat mendidik, baik berupa nilai moral regius (nilai moral tentang hubungan manusia dengan Tuhannya), nilai moral sosial kemasyarakatan (nilai moral tantang hubungan manusia dengan sesame manusia, termasuk dengan dirinya sendiri), ataupun nilai moral pemeliharan dan pelestarian dengan lingkungan alamnya).

\section{Metode Penelitian}

Jenis penelitian ini adalah komparasi, yaitu observasi lapangan dan kajian pustaka. Observasi lapangan dibutuhkan untuk mencari data dan analisa tentang sejarah ketokohan Kiai Imam Malik ditinjau dari berbagai aspek. Serta peninggalan apa saja yang diwariskan oleh Kiai Imam Malik untuk keluarga dan ummat. Selanjutnya latar belakang untuk mengungkapkan makna, konsep berfikir, latar belakang penulisan Kidung Pangiling. Kedua adalah kajian pustaka, mempelajari secara intensif dan mendalam tentang makna yang terkandung dalam tulisan kidung pangiling karya Kiai Imam Malik.

Penelitian ini menggunakan pendekatan deskriptif - interpretative, yaitu usaha untuk menggambarkan penafsiran kidung pangiling karya Kiai Imam Malik sebagai tafsr moral dalam masyarakat. Karena kandungan isinya yang sarat dengan nilai moralitas dan sosial, maka peneliti masih menganggap penting, bahwa kidung pangiling ini masih layak dan penting untuk diketahui dan dipahami oleh publik.

Adapun pengumpulan data menggunakan metode dokumentasi, yaitu dengan mencari data - data mengenai hal - hal atau variable yang berupa catatan, transkip, buku dan sebagainya. ${ }^{2}$ Pengumpulan data juga diperkuat dengan metode interview ${ }^{13}$ kepada orang - orang terdekat Kiai Imam Malik terutama istri, anak - anaknya dan santrinya. Sedangkan analisis data menggunakan Hermeneutik Psikohistoris dan Analisis Deskriptif. Adapun langkah - langkah yang dilakukan dalam penelitian ini adalah peneliti

\footnotetext{
${ }^{11}$ Jenis - jenis ajaran moral dapat dibagi menjadi empat, yaitu : ajaran moral hubungan manusia dengan Tuhan, ajaran moral hubungan manusia dengan manusia, ajaran moral hubungan manusia dengan dirinya sendiri dan ajaran moral hubungan manusia dengan alam. Amirul Nur Wahid dkk, Ajaran Moral Dalam Lirik Lagu Dolanan Anak, Mudra Jurnal Seni Budaya Volume 32, Nomor 2, Mei 2017, 173

12 Suharsimi Arikunto, Prosedur Penelitian SUatu Peneitian Praktek, Jakarta : PT Rineka CIpta, 1993), 206

${ }^{13}$ Chalid Narbuka dan Abu Ahmadi, Metode Penelitian, (Jakarta : Bumi Aksara, 2007), 83
} 
membaca, mencermati, dan memahami serta mendeskripsikan tulisan kidung pangiling karya Kiai Imam Malik, lalu peneliti mencoba memberikan interpretasi terhadap pemikiran Kiai Imam Malik dengan cara melihat keselarasannya dan menetapkan inti pemikiran yang mendasar. Ditinjau dari psikologi Kiai Imam Malik dan sejarah awal munculnya kidung pangiling sebagai langkah tasir moral yang mengalami penurunan secara drastis karena banyaknya pertikaian yang muncul di beberapa daerah seperti Kalimantan, Sulawesi dan Ambon.

\section{Hasil Penelitian}

Kidung Pangiling merupakan syïran yang diciptakan oleh Kiai Imam Malik yang bertempat tinggal di desa Losari kecamatan Mojosari kabupaten Mojokerto. Beliau mendirikan padepokan yang bernama Mayangkoro pondok pesantren Sambung Sari Noto Projo Majapahit Bangkit Nusantara Jaya. Kiai Imam Malik menciptakan syiiran kidung pangiling bertujuan untuk memberikan nasehat ${ }^{14}$ dan pengingat kepada masyarakat pada durasi waktu 1997 - 2006. Syiiran ini ditulis dengan dibantu oleh beberapa santri (Toha, Masnun dkk) menggunakan media alat tulis dan kertas. ${ }^{15}$

Dalam Kidung Pangiling karya Kiai Imam Malik terurai menjadi beberapa bagian, yaitu syiiran yang dituliskan pada tahun 1997, 1998, 1999, 2000, 2001, 2005, 2006 dan akhir. Tafsir moral yang dicantumkan oleh penulis adalah hanya di tahun 1999, 2000 dan 2001, karena banyaknya perpecahan atau perang saudara yang terjadi di Indonesia seperti konflik Kalimantan, Sulawesi dan Ambon.

Kidung Pangiling Tahun 1999

\begin{tabular}{lll}
\hline Akeh wong kalab gak podho & Maknanya adalah banyak orang \\
kroso & yang frustasi tidak merasa \\
Mulai sasi songo tahun 99 & dimulai tahun 99 bulan 9. Orang \\
Wis podho bingung wedi ciloko & semua bingung takut celaka tidak \\
Ora biso nyukuri nikmat seng & mau mensyukuri nikmat yang \\
teko & diberikan kepadanya. & \\
\hline Gagale pemilu ing tahun 99 & Maknanya adalah pemilu gagal \\
\hline
\end{tabular}

${ }^{14}$ Nur Khosi'in, Dakwah Akblak Melalui Literasi (Kajian Terbadap Kitab Syiiran Nasehat Karya K.H. R. Asnawi), JIE Vol. IV No. 1 April 2015, 79

15 Wawancara dengan Abdul Wahab Said, putra pertama Kiai Imam Malik, pada 04 Mei 2018 di Mojokerto 


\begin{tabular}{|c|c|}
\hline $\begin{array}{l}\text { Mung anane coblosan ambal ping } \\
5 \\
\text { Mulo sedulur kudu luwih } \\
\text { waspodo } \\
\text { Mudhune benthoro kolo macak } \\
\text { dewo }\end{array}$ & $\begin{array}{l}\text { ditahun 99, karena banyaknya } \\
\text { kecurangan mulai pencoblosan } \\
\text { berkali kali. Para saudara rus hati - } \\
\text { hati turunnya orang jelek yang } \\
\text { menyerupai kebaikan dewa. }\end{array}$ \\
\hline $\begin{array}{l}\text { Tahun } 2000 \text { jelas rusake } \\
\text { Anane negoro akeh perkarane } \\
\text { Gak iso ngadili ditagih rakyate } \\
\text { Penggedene mbujuk balik awake }\end{array}$ & $\begin{array}{l}\text { Maknanya adalah tahun } 2000 \\
\text { merupakan pertanda kerusakan, } \\
\text { karena Negara mempunyai banyak } \\
\text { permasalahan. Para pengadil tidak } \\
\text { mampu menyikapi dengan hasil yang } \\
\text { baik sehingga rakyat menuntut } \\
\text { keadilan. Para pejabat membohongi } \\
\text { rakyatnya, tetapi kembali kepada } \\
\text { dirinya sendiri. }\end{array}$ \\
\hline $\begin{array}{l}\text { Ketemu gabus iku ngisarahno } \\
\text { Enteke pemimpin kalangan } \\
\text { wibowo } \\
\text { Didobrak rakyat gak iso opo- } \\
\text { opo } \\
\text { Sebab ngentekno duwit negoro }\end{array}$ & $\begin{array}{l}\text { Maknanya adalah banyaknya } \\
\text { pemimpin kehilangan wibawanya, di } \\
\text { demonstrasi oleh rakyatnya tidak bisa } \\
\text { menjwab apa - apa. Karena mereka } \\
\text { menghabiskan uang Negara begitu } \\
\text { saja. }\end{array}$ \\
\hline $\begin{array}{l}\text { Alame genah ndelok pemimpin } \\
\text { Wis ora pantes dadi wong } \\
\text { mukmin } \\
\text { Mlakune ela elo dadine miring } \\
\text { Kanggo gandolan jelas nek } \\
\text { ngoling }\end{array}$ & $\begin{array}{l}\text { Maknanya adalah banyaknya } \\
\text { pemimpin ya tidak beriman karena } \\
\text { perilakunya menyimpang. Mereka } \\
\text { tidak pantas menjadi tempat } \\
\text { bersandar karena jelas akan } \\
\text { menjeruskan. }\end{array}$ \\
\hline $\begin{array}{l}\text { Iki siiran kanggo ngilingno } \\
\text { Tumprap wong islam sak alam } \\
\text { ndunyo } \\
\text { Sarono iling kanti waspodo } \\
\text { Supoyo slamet pengaruhe buto }\end{array}$ & $\begin{array}{l}\text { Maknanya adalah syiiran ini adalah } \\
\text { mengingatkan semua orang Islam di } \\
\text { seluruh dunia. Agar hati - hati dan } \\
\text { waspada supaya selamat dari } \\
\text { pengaruhnya syetan. }\end{array}$ \\
\hline $\begin{array}{l}\text { Iki siiran kudu dipahami } \\
\text { Ati sing bersih sarono teliti } \\
\text { Supoyo paham lan biso ngerti } \\
\text { Anane alam sing bakal dilewati }\end{array}$ & $\begin{array}{l}\text { Maknanya adalah syiiran ini harus } \\
\text { dipahami dengan hati yang bersih } \\
\text { dan teliti. Agar memahami dan } \\
\text { mengerti, adanya proses alam yang }\end{array}$ \\
\hline
\end{tabular}


harus dilewati.

Mulo sedulur podho mikiro

Sing dibarengi eling kang moho

kuoso

Supoyo ngerti rusake tatanan negoro

Supoyo bener belo agomo

Mulo sedulur kang podho iman

Ojo ninggalno anane pranatan

Supoyo slamet akire zaman

Sebab kuate yakine iman
Maknanya adalah semua manusia harus berpikir dengan dibarengi ingat kepada yang Maha Kuasa. Agar mengerti rusakya tatanan Negara supaya benar dalam membela agama.

Maknanya adalah para saudara yang seiman jangan sampai meninggalkan tatanan. Agar selamat di akhir zaman karena kuatnya memegang keyakinan iman.

Umate bingung koyok gabah
dienteri
Akeh pemimpin kurang diteliti
Wong mlaku bener tambah
dibenci
Jelas cocok banget dawuhe nabi

Mulo sedulur ojo kesuwen

Amal sing bagus ojo sampek

leren

Supoyo uripe tetep oleh tameng

Kuate iman sing dadi benteng

Tahun 2000 jelas rusake

Anane negoro akeh perkarane

Gak biso ngadili ditagih rakyate

Penggede mbujuk iku ngisahrono

Mojopahit bangkit iku

dukungane

Sejarah kuno gak keno
Maknanya adalah umat semuanya sedang mengalami kebingungan, karena banyaknya pemimpin kaehilangan ketelitiannya. Orang berjalan dalam kebenaran malah semakin dbenci, hal ini cocok dengan sabdanya Nabi.

Maknanya adalah para saudara jangan berlama - lama, mari beramal baik jangan sampai berhenti. Agar kehidupan mendapatkan pertahanan, kuatnya iman yang menjadi benten pertahanan.

Maknanya adalah tahun 2000 sudah terlihat rusaknya masyarakat karena banyaknya perkara dalam sebuah Negara. Para pengadil tidak mampu mengadili sehingga rakyat bertanya tanya. Hal ini mengakibatkan para pejabat berbohong untuk keamanan sendiri.

Maknanya adalah ngiroh Majapahit itu menjadi pendukung utama, karena sejarah kuno tidak bisa ditinggalkan. 


\begin{tabular}{|c|c|}
\hline $\begin{array}{l}\text { ditinggalne } \\
\text { Negoro wibowo kudu ngerti asale } \\
\text { Supoyo slamet anak turune }\end{array}$ & $\begin{array}{l}\text { Negara berwiwa harus tau asal } \\
\text { usulnya supaya selamat anak } \\
\text { keturunannya. }\end{array}$ \\
\hline $\begin{array}{l}\text { Bersatu padu kudu diutamakno } \\
\text { Bisane sukses mbangun negoro } \\
\text { Dadi wong islam kudu biso } \\
\text { nyegah howo } \\
\text { Kesenengan ndunyo sing } \\
\text { ngalahno agomo }\end{array}$ & $\begin{array}{l}\text { Maknanya adalah bersatu padu harus } \\
\text { diutamakan karena ini adalah kunci } \\
\text { suksenya membangun sebuah } \\
\text { Negara. Menjadi orang Islam harus } \\
\text { mencegah hawa nafsu, kesenangan } \\
\text { dunia yang nantinya akan } \\
\text { mengalahkan agama. }\end{array}$ \\
\hline $\begin{array}{l}\text { Negoro biso makmur yen adil } \\
\text { ditengakno } \\
\text { Mungguh tatanan sing wis } \\
\text { diputusno } \\
\text { Mahkamah agung sing dipercoyo } \\
\text { Supoyo sukses mbangun negoro }\end{array}$ & $\begin{array}{l}\text { Maknanya adalah Negara bisa mamur } \\
\text { apabila keadilan ditegakkan karena } \\
\text { tatanan hukum yang sudah } \\
\text { diputuskan. Mahmakah agung yang } \\
\text { menjadi kepercayaan agar sukses } \\
\text { membangun Negara. }\end{array}$ \\
\hline $\begin{array}{l}\text { Diarani selamet mergo kuat } \\
\text { imane } \\
\text { Ora mergo sugih duwur pangkate } \\
\text { Lamun sugih pangkat kendel } \\
\text { korupsine } \\
\text { Wong keno bendu, neroko } \\
\text { panggonane }\end{array}$ & $\begin{array}{l}\text { Maknanya adalah selamat adalah } \\
\text { orang - orang yang memegang teguh } \\
\text { keimannanya, bukan karena orang } \\
\text { kaya dan tinggi pangkatnya. Percuma } \\
\text { kalau tinggi derajatnya melakukan } \\
\text { korupsi, karena akan mendapatkan } \\
\text { hukuman dari sang Maha Kuasa. }\end{array}$ \\
\hline $\begin{array}{l}\text { Tatanan anyar sing salah kaprah } \\
\text { Sing wis dadi umum, bener tak } \\
\text { lumrah } \\
\text { Sebab ilange hukum lan sejarah } \\
\text { Karek ngenteni tekane banjir } \\
\text { darah }\end{array}$ & $\begin{array}{l}\text { Maknanya adalah sebuah tatanan } \\
\text { Negara yang baru yang salah itu } \\
\text { sudah menjadi identitas dan } \\
\text { kebenaran adalah tirani. Karena } \\
\text { hilangnya hukum dan sejarah } \\
\text { nantinya menunggu sebuah } \\
\text { peperangan dan pertumpahan darah. }\end{array}$ \\
\hline
\end{tabular}

Pada tahun 1999 banyak orang yang merasakan frustasi, orang merasakan ketakutan, kecemasan yang luar biasa, karena tidak mau mensyukuri nikmat yang diberikan Tuhan kepadanya. Pemimpin mulai kehilangan kebiwaannya karena banyak permasalahan yang mendera bangsa ini, demonstrasi terjadi diberbagai penjuru kota. Para pejabat Negara tidak 
mampu membendung problematika karena mereka juga ikut andil dalam permasalahan itu sendiri. Banyak KKN (Korupsi, Kolusi dan Nepotisme) yang mengakar kuat yang terjadi didalam unsur pemerintah baik di daerah maupun di pusat.

Kidung Pangiling ini adalah syiiran yang bertujuan mengingatkan seluruh umat Islam diseluruh dunia. Agar hati - hati dan selalu waspada terhadap berbagai kondisi yang ada terutama masalah godaan syetan. Syiiran ini harus dipahami dengan hati yang bersih dan teliti. Karena proses alam yang terjadi adalah indicator evaluasi diri. Kiai Imam Malik juga mengingatkan semua manusia agar selalu ingat kepada Allah yang maha Kuasa agar mereka memahami rusaknya tatanan Negara dan supaya jalannya benar dalam membela agama. Umat dimasa ini kehilangan pegangan dan mengalami kebingungan karena kebenaran adalah tirani yang justru banyak dibenci.

Kidung Pangiling ini juga menunjukkan kepada kita semua bahwa ghiroh Majapahit, sebuah kerajaan besar di jamannya menjadi motivasi karena sejarah tidak akan bisa hilang. Negara Indonesia pernah menjadi Negara yang besar, dan hal ini didukung karena persatuan dan kesatuan didalamnya. Negara dapat makmur apabila keadilan dapat ditegakkan, dan Mahkamah Agung menjadi kepercayaan rakyat untuk membangun Negara dengan baik. Didalam bait yang lain berisikan tentang keluhuran seseorang tidak hanya dipandang secara material semata, tetapi keteguhan untuk selalu memegang keimanan dan kejujuran.

Bila ditengok lagi tahun 1999 menorehkan sejarah penuh darah yaitu konflik suku Melayu (Sambas) dengan suku Madura. Sekitar 1800 tempat tinggal hancur, banyak nyawa melayang dan kerugian materi atau infrastruktur (tanah, sawah, kebun dan hewan ternak) yang diakibatkan dari tragedy tersebut tidak terhitung. Kini konflik kekerasan telah berakhir namun statusnya konflik masih pada tarap simmering yaitu belum terselesaikan akar konfliknya. Hal ini dibuktikan dengan tidak diperkenankannya suku Madura kembali ke Sambas. Selain itu semakin berkembangnya embrio prasangka negative. $^{16}$

Apa yang menarik dalam kasus - kasus konflik antar suku bangsa di Sambas (Melayu lawan Madura), Ambon (Ambon lawan Buton, Bugis dan

\footnotetext{
${ }^{16}$ Eka Hendry Ar dk, Integrasi Sosial Dalam Masyarakat Multi Etnik, Walisongo, Volume 21, Nomor 1, Mei 2013, 192
} 
Makasar) pada tahap permulaan, dan Kalimantan Tengah (Dayak lawan Madura) adalah bahwa konflik tersebut telah terjadi antara warga pendatang dengan pribumi setempat. Dalam konflik ini, penduduk pribumi atau suku bangsa setempat berusaha mengambil alih kembali sumber daya yang mereka miliki yang telah diambil oleh suku pendatang. Kelompok suku bangsa setempat melakukannya dengan cara kekerasan dan terror yang sama, atau bahkan lebih mengerikan daripada yang telah dilakukan oleh pendatang. Mereka melakukan pengembalian pola kehidupan berdasarkan keudayaan mereka sendiri yang terwujud sebagai adat atau tatatnan sosial yang sebelumnya berlaku, yang mereka anggap sebagai yang benar, adil dan beradab.

Adanya isu perang agama untuk mengambarkan konflik antar suku bangsa yang terjadi di kabupaten Sambas tahun 1997 antara Madura - Dayak, tahun 1999 antara Madura - Melayu yang diikuti konflik antara Madura Dayak, di Ambon pada tahun 1999 antara BBM - Ambon, dan diantaranya Madura - Dayak di Kalimantan Tengah. Isu bahwa konflik Madura - Dayak di Sanggi Ledo, Sambas, pada tahun 1997 sebagai perang agama muncul pada tahun 1997 - 1998. Mereka mengatakan bahwa konflik Madura - Dayak adalah konflik anatara Kristen dengan Islam. ${ }^{17}$

Konflik sosial dalam masyarakat diakibatkan beberapa factor : pertama, perbedaan pendiran atau perasaan individu. Kedua, perbedaan latar belakang kebudyaan juga berpotensi menimbulakan konflik. Ketiga, perbedaan kepentingan antara individu atau kelompok, baik menyangkut politik, ekonomi, sosial, budaya atau agama. Keempat, perubahan nilai yang cepat dan mendadak dalam masyarakat. Secara spesifik konflik sosial berbau agama di Indonesia disebabkan misalnya :

1. Adanya klaim kebenaran, pluralitas manusia menyebabkan kebenaran diinterpretasikan secara berbeda dan dipahami secara absolut.

2. Wilayah agama dan suku semakin kabur

3. Doktrin jihad yang dipahami secara sempit

4. Kurangnya sikap toleransi dalam beragama

5. Minimnya pemahaman terhadap ideology pluralisme ${ }^{18}$

\footnotetext{
${ }^{17}$ Parsudi Suparlan, Keyakinan Keagamaan Dalam Konflik Antar Suku Bangsa, Natropologi Indonesia, 66, 2001, 28

18 St. Aisyah BM, Konflike Sosial Dalam Hubungan Antar Umat Beragama, Jurnal Dakwah Tabligh, Vol. 15, No. 2, Desember 2014, 197
} 
Konflik Maluku merupakan konflik horizontal yang terjadi penduduk yang beragama Islam dan Kristen. Konflik ini dipicu oleh banyak factor, seperti ekonomi dan politik yang kemudian dibawa dalam ranah sentiment ras dan agama. Berbagai upaya penyelesaian sudah dilakukan ileh banyak kalangan, Pemerintah, LSM, Lembaga Adat dan gerakan akar rumput masyarakat lainnya yang terbentuk karena keprihatinan akan konflik yang berkepanjangan. Segregasi sosial yang menjadi warisan peninggalan Belanda belum bisa dihilangkan dan semakin tajam dengan adanya konflik antar kedua suku agam tersebut. ${ }^{19}$ Konflik ini bermua dari pertikaian antara sopir angkot, Jacob Lauhery yang beragama Kristen dengan Nursalim seorang Islam dari Batu Merah keturunan Bugis. Konflik kemudian berkembang menjadi konflik agama (Islam dan Kristen), di Maluku Utara konflik juga terjadi di tingkatan lokal, menimbulakan polarisasi di masyarakat hingga konflik etnis dan agama. Factor lain ini adalah perebutan kekuasaan karena bertentangan dengan hukum adat. ${ }^{20}$

E. Kidung Pangiling Tahun 2000

\begin{tabular}{ll}
\hline $\begin{array}{l}\text { Hukum agomo tambah } \\
\text { dikalahno }\end{array}$ & $\begin{array}{l}\text { Maknanya adalah hukum agama } \\
\text { dapat dikalahkan denga akal }\end{array}$ \\
Karo akale sifate menungso & sifatnya manusia. Hal ini \\
Dadine kafir podho ora rumongso & menjadikan seseorang kafir secara \\
Saking senenge nglabuhi harto & tidak sengaja karena kecintaan \\
& terhadap dunia sehingga \\
& hidupnya dapat dikelabuhi. \\
\hline Akeh mubalik dadi harmoko & Maknanya adalah banyak seorang \\
Dadi tontonan ora podho & ustadz menjadi tokoh seperti \\
rumongso & Harmoko, menjadi tontonan dan \\
Wujude rusak tatanan negoro & mereka tidak merasa. Hal ini \\
Penguoso kalah karo wong ndeso & berakibat terhadap rusaknya tatanan \\
& Negara. Sehingga pemimpin kalah \\
\hline
\end{tabular}

${ }_{19}$ Ernita Krisandi dkk, Resolusi Konflik Komunal di Maluku Pasca Reformasi, Jurnal Ilmu Pemerintahan, Vol, Nomor, Tahun 2013, 1

${ }^{20}$ Jamin Safi, Knflik. Komunal Maluku 1999 - 2000, Volume 12, No. 2 Maret 2017, 33 
dibandingkan orang desa.

Mulo sedulur ojo kesuwen Maknanya adalah ayo saudara jangan

Amal seng bagus ojok sampek terlalu lama, mari beramal dalam

leren

kebaikan jangan sampai berhenti.

Supoyo uripe tetep oleh tameng Agar kehidupan ini menjadi benteng

Kuate iman sing dadi benteng dalam hal ini adalah keimanan.

Mulo sedulur ojo salah paham Maknanya adalah para saudaraku Lan opo maneh tumrap wong jangan sampai pernah salah faham islam apalagi sesame orang muslim. Sudah Wis podho ngerti dawuhe al tau semua kan tentang penjelasan quran dari Al - Qur'an kalau kita tidak Yen ora manut mesti kecemplung menjalankannya maka akan masuk ke jurang jurang.

Bisone slamet kudu iling lan Agar selamat harus ingat dan waspodo waspada, menjalankan dan Lakune abot nyekel agomo memegang prinsip keagamaan. Menurut hadis koyok nggegem Menurut hadisnya memang berat mowo Sing sopo kuat dadine mulyo diibaratkan memegang api. Apabila kita kuat maka kemulyaan akan kita dapatkan.

Dalam Kidung Pangiling ini juga dipaparkan hukum agama akan dikalahkan oleh kepentingan manusia semata. Hal ini menjadikan manusia seolah - olah kafir secara sendirinya, karena kecintaan terhadap dunia mengalahkan kepentingan ibadahnya. Munculnya banyak ustadz atau guru agama seperti tokoh Harmoko, tokoh yang penuh dengan kontrofersial, disatu sisi tokoh ini merupakan tokoh yang sangat disegani di Zamannya Presiden Soeharto, bahkan disebut - sebut orang kepercayaannya. Akan tetapi setelah Soeharto lengser, tokoh ini adalah bagian dari actor intelektual yang juga memprovokasi dan menurunkan atau tidak sepakat dengan konsep kepemimpinan Presiden Soeharto.

Harmoko merupakan orang yang terlahir dari keluarga sederhana, namun memiliki perhatian pada seni dan pengetahuan. Karir Harmoko terus naik saat ia menjadi wartawan sampai ia menjadi pemilik sebuah media yang memiliki oplah terbesar pada masa Orde Baru yaitu Pos Kota. Keberhasilan Harmoko dalam Pos Kota menarik perhatian Soeharto sehingga diangkat 
menjadi Menteri Penerangan. Dengan kepiawaiannya Harmoko berhasil memenangkan pemilu 1997 sebesar 74, 3 \%. Ketika reformasi menginginkan rezim Orde Baru dijatuhkan Harmoko memberi keputusan untuk menghianati Soehaerto dengan menyuruhnya turun dari jabatannya. Harmoko memiliki kepatuhan tinggi, bertanggung jawab, pengabdian dan jujur kepada Soeharto sebagai petingginya. Walaupun demikian ia menjadi pemberontak karena mereka utamakan keamanan diri, hal ini dikarenakan rakyat yang dianggpanya mengancamnya. ${ }^{21}$

\section{F. Kidung Pangiling Tahun 2001}

2001 petnege jagad

Moral rohani wis podho bejad

Wis ora nompo arane wasiat

Sebab rotone aran maksiyat
Maknanya adalah gelapnya dunia karena moral manusia sudah diambang batas. Sudah tidak bersedia diberikan nasehat karena semua sudah familiar dengan maksiat.

Ilange syukur tekane bendu Jelas morat marit ing tahun 2000 Wong mlaku bener luwih wedi mergo disatru

Murkane masa nuruti nafsu

Maknanya adalah hilangnya syukur kepada sang Maha Kuasa menyebabkan bencana dan ini terjadi di tahun 2000. Orang berjalan dengan benar malah takut salah karena dimusuhi oleh banyak orang, marahnya manusia dipicu hawa nafsunya.

Akeh kebohongan yo akeh Maknanya adalah banyaknya kematian

Akeh tanah longsor yo kebanjiran Petani nagis mergo kerugian Pedagang kemplengkang mergo akehe kerusakan

Poro pejabat wis podho dadi penjahat

Goro-gorone ulama podho mecetat

kebohongan juga kematian.

Munculnya bencana tanah longsor juga kebanjiran. Petani menangis karena merugi dan pedagang mengalami banyak kerusakan.

Maknanya adalah pejabat menjelma menjadi penjahat, karena ulama sama - sama cacat. Semua mengalami kebimbangan karena

${ }^{21}$ Gina Siti Rahmah, Kiprah Politik Harmoko Pada Masa Orde Baru Melalui Analisi Biografi (1983 - 1999), Factum, Volume 5, Nomor 2, Oktober 2016, 218 


\begin{tabular}{ll}
\hline Podho kebimbang duit lan & uang dan pangkat, orang tidak sadar \\
pangkat & sudah kehilangan derajat dan \\
Gak podho kroso ngilangno drajat & martabat. \\
\hline
\end{tabular}

Konflik poso sebenarnya adalah konflik realistic yaitu perbeutan kekuasaan politik antara elit politik lokal di Poso yag dikemudian massa dilibatkan dengan identitas agama dan etnis dengan tujuan untuk memobilisasi massa dalam memperoleh kekuasaan. Ketika konflik menyentuh ranah agama membuat pertikaian menjadi konflik non realistic bernuansa SARA dan menjadikan konflik terjadi berkepanjangan. Mudahnya massa termobilisasi dalam konflik komunal di Poso, dipengaruhi juga oleh permasalahan historis yang dimanfaatkan oleh elit politik lokal melalui isu berupa kecemburuan sosial - ekonomi dan sosial - politik antara penduduk pribumi yaitu etnis Pamona, Mori dan Lore (mayoritas beragama Kristen ) yang merasa termarjinalkan terhadap kehadiran dari etnis Jawa, Bugis dan Makasar (mayoritas beragama Islam). Upaya perdamaian yang sangat berpengaruh hasilnya dalam menghentikan konflik Poso adalah setelah turun tangannya pemerintah pusat melalui Menko Kesra yang ditunjuk menjadi pemimpin mediator upaya damai di Poso. ${ }^{22}$

Beberapa solusi yang ditawarkan dalam meredam konflik di tahun 2001 adalah :

1. Penyelesaian diserahkan untuk ditangani oleh lembaga independen yang beranggotakan tokoh dari kedua etnik serta kalangan intelektual dan tokoh kredibel dari pemerintahan yang difasilitasi sepenuhnya oleh Negara.

2. Siapapun yang diindikasikan kuat sebagai actor intelektual di balik kerusuhan di Kateng, baik kalangan Dayak dan Madura harus ditangkap dan dibawa ke pengadilan.

3. Negara harus membantu warga etnis Madura untuk mendapatkan kembali hak milik mereka berupa asset ekonomi terutama tanah serta rumah tempat tinggal.

22 Igneus Alganih, Konflik Poso (Kajian Historis Tabun 1998 - 2001), Jurnal Criksetra, Volume 5, Nomor 10, Agustus 2016, 173 
4. Negara bekerjasam dengan LSM melakukan sosialisasi dan kampanye terus menerus dalam berbagai bentuk tentang kenyataan Indonesia sebagai bangsa majemuk. ${ }^{23}$

Ada beberapa saran untuk penyelesaian konflik diantaranya :

1. Kepada pemerintah pusat dan daerah hendaknya mengedepankan pendekatan politik regognisi dalam penyelesaian konflik multicultural yang terjadi di Indonesia, yaitu dengan mengedepankan fasilitas untuk mengakomodasi inisiatif - kultural dari bawah, menuangkan kesepakatan kultural dari bawah dalam kebijakan public yang memungkinkan setiap pihak hidup berdampingan secara damai.

2. Kepada perguruan tinggi dan masyarakat sipil hendaknya melakukan diseminasi penyelesaian konflik secara partisipatoris, berwatak bootom - up dan berfokus pada inklusi secara sosio - ekonomi - politik.

3. Kepada peneliti lain, hendaknya melakukan penelitian lain lebih lanjut untuk memperkuat state of the arti penyelesaian konflik multicultural khas Indonesia dan berkontribusi menyelesaikan konflik multicultural yang terjadi di Indonesia yang majemuk. ${ }^{24}$

\section{Kesimpulan}

Kidung Pangiling ini adalah syiiran yang bertujuan mengingatkan seluruh umat Islam diseluruh dunia. Agar hati - hati dan selalu waspada terhadap berbagai kondisi yang ada terutama masalah godaan syetan. Syiiran ini harus dipahami dengan hati yang bersih dan teliti. Karena proses alam yang terjadi adalah indicator evaluasi diri. Kiai Imam Malik juga mengingatkan semua manusia agar selalu ingat kepada Allah yang maha Kuasa agar mereka memahami rusaknya tatanan Negara dan supaya jalannya benar dalam membela agama. Umat dimasa ini kehilangan pegangan dan mengalami kebingungan karena kebenaran adalah tirani yang justru banyak dibenci.

${ }^{23}$ Rusikan, Konflik Dayak - Madura di Kalimantan Tengah : Melacak Akar Masalab dan Tawaran Solusi, Masyarakat, Kebudayaan dan Politik, Tahun XIV, Nomor 4, Oktober 2001, 12

${ }^{24}$ Suharno dkk, Pengembangan Model Resolusi Konflik. Untuk. Masyarakat MUltikultural (Studi Implementasi Kebijakan Resolusi Konflik di Sampit, Poso dan Ambon, 26 
Kidung Pangiling ini juga menunjukkan kepada kita semua bahwa ghiroh Majapahit, sebuah kerajaan besar di jamannya menjadi motivasi karena sejarah tidak akan bisa hilang. Negara Indonesia pernah menjadi Negara yang besar, dan hal ini didukung karena persatuan dan kesatuan didalamnya. Negara dapat makmur apabila keadilan dapat ditegakkan, dan Mahkamah Agung menjadi kepercayaan rakyat untuk membangun Negara dengan baik. Didalam bait yang lain berisikan tentang keluhuran seseorang tidak hanya dipandang secara material semata, tetapi keteguhan untuk selalu memegang keimanan dan kejujuran.

\section{Referensi}

Agung Satriyo Nugroho, A Semantic Analysis of Denotative Meaning in Kidung DOA Song by Sunan Kalijaga, Jurnal Ilmiah Bahasa dan Sastra, Vol 3, No. 1, Juni 2016

Alganih Igneus, Konflik Poso (Kajian Historis Tabun 1998 - 2001), Jurnal Criksetra, Volume 5, Nomor 10, Agustus 2016

Arikunto Suharsimi, Prosedur Penelitian SUatu Peneitian Praktek, (Jakarta : PT Rineka CIpta, 1993)

Artana I Wayan, Pengaruh Budaya Bali Kidung Warga Sari TErhadap Tekanan Darah Pada Lansia di Banjar Celuk Desa Dalung Badung, Jurnal Dunia Kesehatan, Vol 5 Nomor 2

Ayu dkk, Kajian Interaksionisme Simbolik Kidung Jula Juli Pada Pementasan Ludruk

Irama Budaya Surabaya, Jurnal Ilmiah : Fonema, Vol 4 No. 2, Bulan Desember 2017

Bahtiar Hafid Zuhdan, Kidung : Myth of Welfare for Kutubuk People in Kudus Regency, Harmonia : Journal of Art Research and Eduacation 14 (2) 2014

Hasanah Uswatun, Nilai Moral Dalam Saq Al-Bambu Karya Saud Al-San'usi, Adabiyyat: Jurnal Bahasa dan Sastra Vol. I, No. 1, Juni 2017

Hendry Eka dkk, Integrasi Sosial Dalam Masyarakat Multi Etnik, Walisongo, Volume 21, Nomor 1, Mei 2013

I'anah Dwi Maftuhatul, Aspek Moral Dalam Novel Mimilan Mintuna Karya Remy Sylado Tinjauan Sosiologi Sastra

Khosi'in Nur, Dakwah Akblak Melalui Literasi Kajian Terhadap Kitab Syïran Nasehat Karya K.H. R. Asnawi), JIE Vol. IV No. 1 April 2015 
Krisandi Ernita dkk, Resolusi Konflik. Komunal di Maluku Pasca Reformasi, Jurnal Ilmu Pemerintahan, Vol, Nomor, Tahun 2013

Lado Susana Fitriani dkk, Analisis Struktur dan Nilai - Nilai Moral yang terkandung Dalam Cerpen Ten Made Todoke Karya Yoshida Genjiro, Jurnal Japanese Literature Volume 2, Nomor 2, Tahun 2016

Narbuka Chalid dan Abu Ahmadi, Metode Penelitian, (Jakarta : Bumi Aksara, 2007)

Nurhata, Naskah Kidung Nabi : Analisis Tema dan FUngsi Sosial, Metasastra : Jurnal Penelitian Sastra, Vol. 10, No. 1, Juni 2017

Nurhasanah Een, Nilai - nilai Kearifan Lokal Dalam Tia Nyanyian Pembuka Pertunjukan Tari Jaipong, Prosiding Seinar Nasional Pendidikan FKIP UNTIRTA 2017

Rahmah Gina Siti, Kiprah Politik Harmoko Pada Masa Orde Baru Melalui Analisi Biografi (1983 - 1999), Factum, Volume 5, Nomor 2, Oktober 2016

Rusikan, Konflik Dayak - Madura di Kalimantan Tengah : Melacak Akar Masalah dan Tawaran Solusi, Masyarakat, Kebudayaan dan Politik, Tahun XIV, Nomor 4, Oktober 2001

Safi Jamin, Konflik. Komunal Maluku 1999 - 2000, Volume 12, No. 2 Maret 2017

Suparlan Parsudi, Keyakinan Keagamaan Dalam Konflik. Antar Suku Bangsa, Natropologi Indonesia, 66, 2001

Suharno dkk, Pengembangan Model Resolusi Konflik Untuk Masyarakat Multikultural (Studi Implementasi Kebijakan Resolusi Konflik di Sampit, Poso dan Ambon

St. Aisyah BM, Konflik Sosial Dalam Hubungan Antar Umat Beragama, Jurnal Dakwah Tabligh, Vol. 15, No. 2, Desember 2014

Traeni Ni Nyiman Tanjung, Bentuk, Fungsi dan Mana Tradisi Lisan "Mabebasas" dalam Upacara Keagamaan di Jawa Timur, (Surabaya : Jurnal Balai Bahasa Surabaya, 2011)

Wahid Amirul Nur dkk, Ajaran Moral Dalam Lirik Lagu Dolanan Anak, Mudra Jurnal Seni Budaya Volume 32, Nomor 2, Mei 2017 